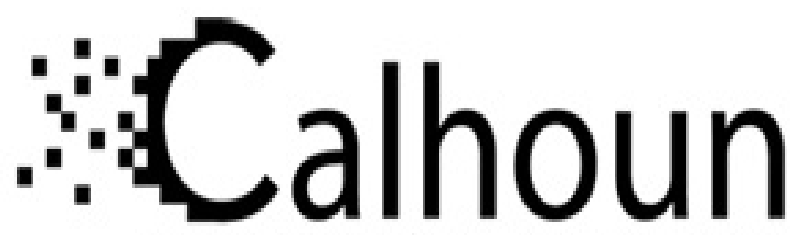

Institutional Archive of the Naval Postgraduate School

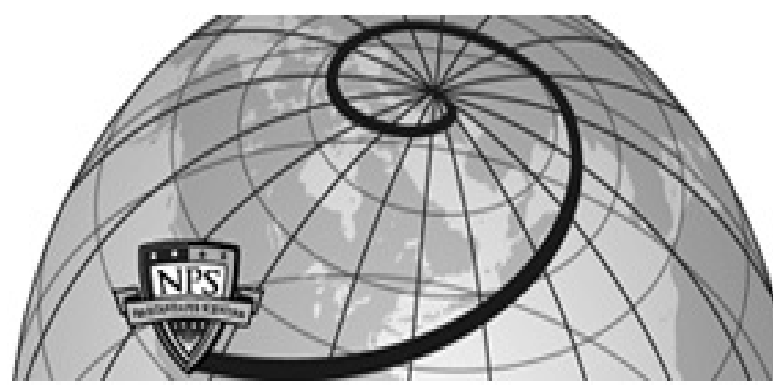

Calhoun: The NPS Institutional Archive

DSpace Repository

\title{
Surfzone Monitoring Using Rotary Wing Unmanned Aerial Vehicles
}

Brouwer, Ronald L.; De Schipper, Matthiew A.; Rynne, Patrick F.; Graham, Fiona J.; Reniers, J.H.M.; MacMahan, Jamie $\mathrm{H}$.

Journal of Atmospheric and Oceanic Technology, Volume 32, pp. 855-863, April 2015 https://hdl.handle.net/10945/45784

This publication is a work of the U.S. Government as defined in Title 17, United States Code, Section 101. Copyright protection is not available for this work in the United States.

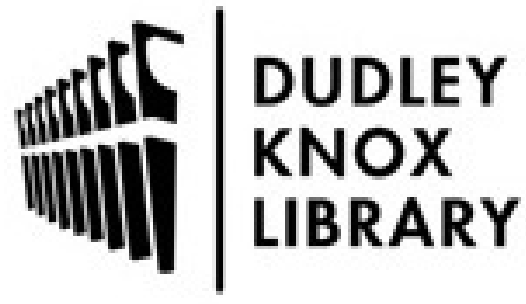

http://www.nps.edu/library
Calhoun is the Naval Postgraduate School's public access digital repository for research materials and institutional publications created by the NPS community. Calhoun is named for Professor of Mathematics Guy K. Calhoun, NPS's first appointed -- and published -- scholarly author.

Dudley Knox Library / Naval Postgraduate School 411 Dyer Road / 1 University Circle Monterey, California USA 93943 


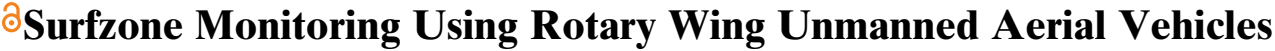

\author{
RonAlD L. BRouWER* AND MATTHIEU A. DE SCHIPPER \\ Hydraulic Engineering Department, Delft University of Technology, Delft, Netherlands \\ PATRICK F. RYNNE, FiONA J. GRAHAM, AND AD J. H. M. RENIERS ${ }^{+}$ \\ Applied Marine Physics, University of Miami, Miami, Florida \\ JAMIE H. MACMAHAN \\ Oceanography Department, Naval Postgraduate School, Monterey, California
}

(Manuscript received 26 June 2014, in final form 20 October 2014)

\begin{abstract}
This study investigates the potential of rotary wing unmanned aerial vehicles (UAVs) to monitor the surfzone. This paper shows that these UAVs are extremely flexible surveying platforms that can gather nearcontinuous moderate spatial resolution and high temporal resolution imagery from a fixed position high above a study site. The rotary wing UAVs used in this study can fly for $\sim 12$ min with a mean loiter radius of $1-3.5 \mathrm{~m}$ and a mean loiter error of $0.75-4.5 \mathrm{~m}$. These numbers depend on the environmental conditions, flying style, battery type, and vehicle type. The images obtained from the UAVs, and in combination with surveyed ground control points (GCPs), can be georectified to a pixel resolution between 0.01 and $1 \mathrm{~m}$, and a reprojection error-that is, the difference between the surveyed GPS location of a GCP and the location of the GCP obtained from the georectified image - of $O(1 \mathrm{~m})$. The flexibility of rotary wing UAVs provides moderate spatial resolution and high temporal resolution imagery, which are highly suitable to quickly obtain surfzone and beach characteristics in response to storms or for day-to-day beach safety information, as well as scientific pursuits of surfzone kinematics on different spatial and temporal scales, and dispersion and advection estimates of pollutants.
\end{abstract}

\section{Introduction}

Unmanned aerial vehicles (UAVs) are relatively small, remotely operated aircraft that are becoming increasingly popular as environmental surveying platforms. Compared to other airborne optical surveying platforms, one of the main reasons for their increasing popularity is their ease in obtaining high-resolution imagery at a moderate

๑ Denotes Open Access content.

\footnotetext{
* Current affiliation: Flanders Hydraulic Research, Antwerp, Belgium.

${ }^{+}$Current affiliation: Delft University of Technology, Delft, Netherlands.
}

Corresponding author address: Ronald L. Brouwer, Flanders Hydraulic Research, Berchemlei 115, B-2140 Antwerp, Belgium. E-mail: ronald.brouwer@mow.vlaanderen.be spatial and high temporal scale in environments that do not support a high vantage point (Table 1). Historically, small UAVs were costly; required specialized training; and were limited by low-amperage, heavy batteries. Early applications focused primarily on military and public safety activities for inspection, reconnaissance, and surveillance. In recent years the arrival of lightweight, highcapacity batteries, low-power electronics, and compact high-definition cameras has driven the development of commercially available UAVs for hobbyists. The low operation costs have increased their potential for scientific research. New applications include mapping and monitoring agriculture (e.g., Zhang and Kovacs 2012; Rasmussen et al. 2013), archeology (e.g., Rinaudo et al. 2012), meteorology (e.g., Rogers and Finn 2013), and marine fauna (e.g., Hodgson et al. 2013), among others.

UAVs are separated into two classes: fixed wing vehicles, which resemble a small airplane; and rotary wing vehicles, which resemble a helicopter but with multiple propellers rotating in the horizontal plane (see Fig. 1). 
TABLE 1. Comparison of airborne optical surveying platforms.

\begin{tabular}{|c|c|c|c|c|c|c|c|}
\hline Monitoring platform & $\begin{array}{l}\text { Operational } \\
\text { altitude }(\mathrm{km})\end{array}$ & Endurance & $\begin{array}{l}\text { Range } \\
(\mathrm{km})\end{array}$ & Flexibility $^{\mathrm{a}}$ & $\begin{array}{l}\text { Temporal } \\
\text { scale }^{b}(\mathrm{~s})\end{array}$ & $\begin{array}{l}\text { Payload } \\
\text { (kg) }\end{array}$ & $\begin{array}{l}\text { Acquisition } \\
\text { cost (US\$) }\end{array}$ \\
\hline Satellite & $>160$ & $O(1-10 \mathrm{yr})$ & Global & Low & $>300$ & $\mathrm{NLF}^{\mathrm{c}}$ & $>300$ million \\
\hline Aircraft ${ }^{\mathrm{d}}$ & $0.3-12.5$ & $\sim 4 \mathrm{~h}$ & $100-1000$ & Medium & $1-300$ & $\mathrm{NLF}^{\mathrm{c}}$ & $200 \mathrm{~K}-2$ million \\
\hline Small fixed wing UAV & $<0.15$ & $<3.5 \mathrm{~h}$ & $<15$ & Medium & $1-300$ & $<10^{\mathrm{e}}$ & $1.5 \mathrm{~K}-50 \mathrm{~K}$ \\
\hline Small rotary wing UAV & $<0.15$ & $<50 \min$ & $<5$ & High & $<1$ & $<10^{\mathrm{e}}$ & $1.5 \mathrm{~K}-20 \mathrm{~K}$ \\
\hline Fixed line helium kite & $<0.10-0.15^{\mathrm{f}}$ & $O$ (h-days) & $\sim 1-20^{\mathrm{g}}$ & Medium & $<1$ & $<30^{\mathrm{e}}$ & $0.2 \mathrm{~K}-2 \mathrm{~K}$ \\
\hline Argus station & $\sim 0.02-0.04^{\mathrm{h}}$ & - & $<8$ & Low & $<1$ & $\mathrm{NLF}^{\mathrm{c}}$ & $\sim 40 \mathrm{~K}$ \\
\hline
\end{tabular}

${ }^{\text {a }}$ Event response time, ease of launching/landing procedures, maneuverability.

${ }^{\mathrm{b}}$ Temporal resolution of consecutive images of the same area; highly dependent on camera type.

${ }^{\mathrm{c}}$ Not a limiting factor.

${ }^{\mathrm{d}}$ Light-class helicopters and private planes.

${ }^{\mathrm{e}}$ Highly dependent on platform type.

${ }^{\mathrm{f}}$ Dutch air traffic and U.S. Federal Aviation Administration regulations.

${ }^{g}$ Depending on physical condition operator(s) and possibility to walk along the beach.

${ }^{\mathrm{h}}$ Depending on building/tower height or natural objects, such as cliffs.

Small, fixed wing UAVs have existed for over two decades and currently have flight durations up to $3.5 \mathrm{~h}$ and cruising speeds up to $80 \mathrm{~km} \mathrm{~h}^{-1}$. The combination of high speed and long flight duration allows for photogrammatic mapping of large areas at high spatial resolution (e.g., G. Pennucci et al. 2008, unpublished manuscript). In contrast, rotary wing UAVs (Fig. 1) exhibit shorter flight durations (up to $50 \mathrm{~min}$ ) and slower cruising speeds (up to $20 \mathrm{~km} \mathrm{~h}^{-1}$ ). However, they are capable of loitering at a fixed position, holding a steady field of view (FOV) for extended periods of time, thus providing moderate spatial and high temporal resolution. Their ability to fly in any direction with no requirement for a runway greatly simplifies launching and landing procedures, making them an ideal instrument for monitoring otherwise difficult-to-access and highly dynamic areas, in particular surfzones.

Surfzones, defined as the areas of breaking waves, control the arrival of biota and pollutants at the beach and are important for recreation and swimmer safety, where rip currents can take swimmers involuntarily offshore (Dalrymple et al. 2011). Surfzone kinematics are notoriously difficult to measure due to large gradients in fluid motions of different spatial and temporal scales (Battjes 1988; Peregrine 1998). For instance, Eulerian in situ measurements can accurately capture the temporal variability of the kinematics but cannot provide large spatial coverage without a significant number of sensors, making it cost prohibitive. Our understanding of the beach morphology and surfzone processes has dramatically increased, owing to long-term video monitoring stations such as Argus (Holman and Stanley 2007, and references therein). Video monitoring, either short term or long term, requires a high-vantage point, such as a large tower, cliff, or a tall hotel adjacent to the beach. In addition, the oblique angle of the camera results in nonequidistant pixel resolution, which increases with distance away from the camera. The rotary-wing UAV can operate directly above the surfzone, providing better pixel resolution for capturing successive images at a fraction of the cost. This allows for a whole new approach for studying the surfzone and beach processes that were previously unavailable. Two rotary wing UAVs, their operational use, and errors are discussed in context with a unique surfzone monitoring effort.

\section{Methods}

\section{a. SCOPE}

The Surfzone Coastal Oil Pathways Experiment (SCOPE) to examine the surfzone control on oil transport on a sandy, rip-channeled beach with a crescentic outer bar system was performed on Fort Walton Beach, Okaloosa Island, Florida, in December 2013. Several UAV monitoring missions were flown on 9-15 December with varying Rhodamine WT (water tracing; $20 \%$ by concentration) dye releases (continuous, blob, and streaks) both outside and inside the surfzone to augment an array of in situ instruments. Since dye is difficult to track with fixed in situ sensors, video monitoring from a high vantage point was required to complement the in situ observations.

\section{b. UAV systems}

Two types of commercial rotary wing UAVs, the Aerialtronics Altura AT6 (Fig. 1a) and the 3D Robotics Y6 (Fig. 1b), were flown for monitoring the surfzone. Both systems are hexacopters, where the three-strut configuration of the Y6 has additional advantages over the AT6, in that the former provides a larger, unobstructed view and that the propeller layout is stable 
a)

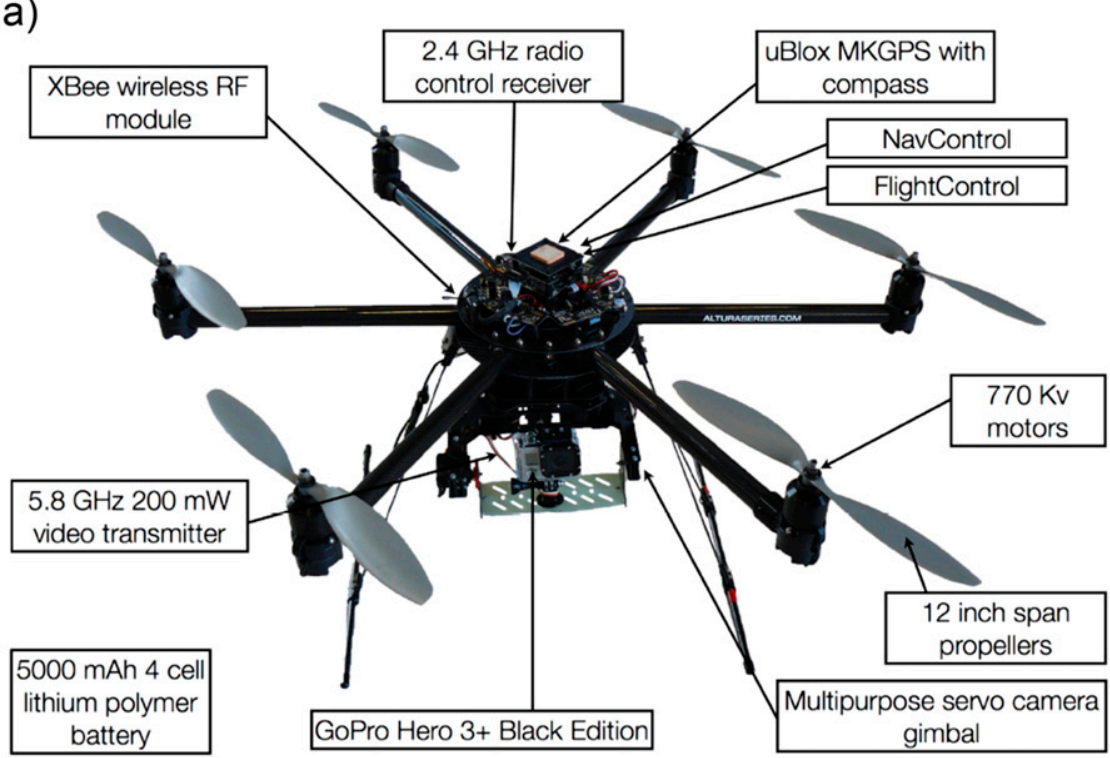

b)

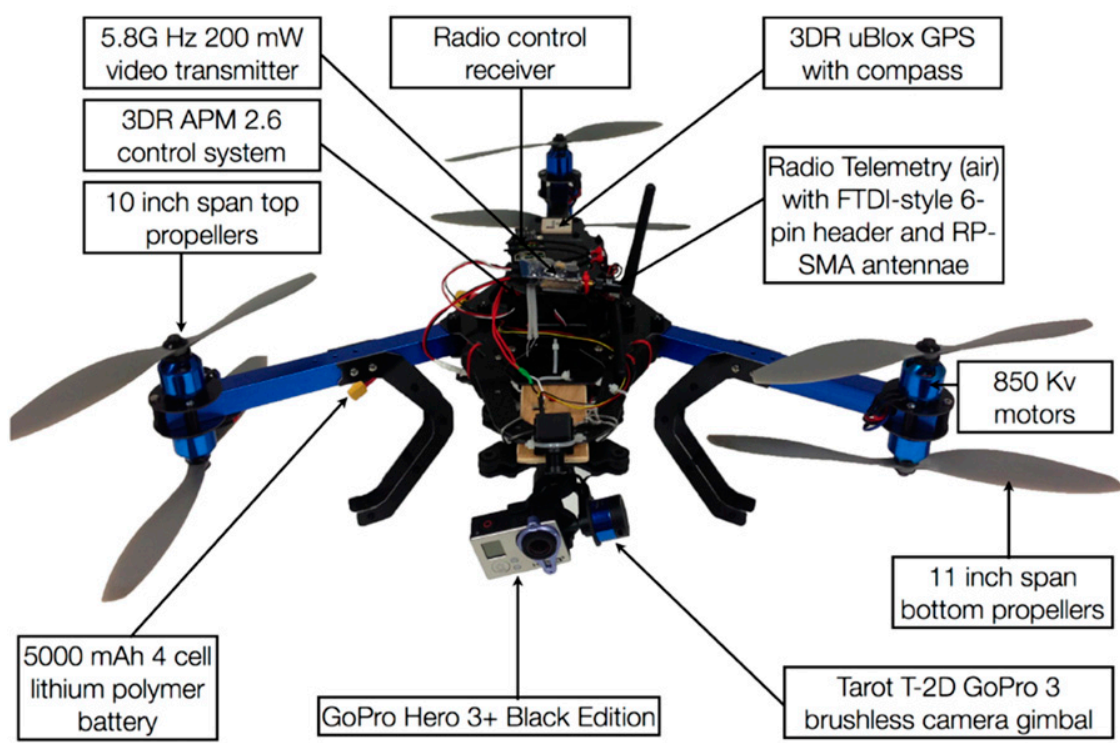

FIG. 1. The UAV systems deployed during SCOPE. (a) The six-strutted hexacopter Altura AT6 equipped with a control system consisting of three gyroscopes, three accelerometers, three magnetometers, a GPS receiver, and a barometric pressure sensor. (b) The three-strutted hexacopter Y6, which utilizes the open source APM 2.6 control system with a built-in three-axis gyroscope, accelerometer, and barometric sensor, and an external GPS and digital compass.

with only five of the blades spinning. The latter provides important redundancy in the event of a motor failure while operating over water. UAV navigation is performed autonomously with planned missions and waypoints or remotely with radio control. The onboard flight controller is capable of stabilizing and holding position and altitude of the UAV based on the internal sensors (Fig. 1). UAV data are stored on board and transmitted to the operator in real time at a frequency of 2400 and $915 \mathrm{MHz}$ for the AT6 and Y6, respectively. A live feed from the onboard camera is transmitted at a frequency of $5.8 \mathrm{GHz}$ for both systems. Both UAVs are powered from a 5000-mAh, four-cell lithium polymer battery. 


\section{c. Camera and lens correction}

During SCOPE, both UAVs were equipped with GoPro Hero $3^{+}$Black edition cameras and stabilized with gyroscopic gimbals capable of precise pitch control by the operator. This camera has two main advantages that are particularly useful in combination with UAVs: 1) it is lightweight $(74 \mathrm{~g})$, resulting in longer flying times; and 2 ) it has a large FOV due to the fish-eye lens (horizontal $\mathrm{FOV}=122.6^{\circ}$, vertical FOV $=94.4^{\circ}$ ), which is necessary to capture large areas from a limited altitude. With a targeted operating altitude of $120 \mathrm{~m}$ and an inclined viewing angle of the camera, a typical ground coverage $O(1 \mathrm{~km})$ alongshore and $O(0.5 \mathrm{~km})$ cross-shore can be achieved (Fig. 2).

Correcting the lens distortion generally requires the determination of the intrinsic camera parameters, that is, focal length, principal point, and distortion coefficients. There are several techniques available to determine these intrinsic camera parameters, for example, Tsai (1987), Heikkilä and Silvén (1997), Zhang (1999), and Kannala and Brandt (2006). In addition, there are several ready-to-use toolboxes available, for example, Bouguet's (2014) calibration toolbox, Scaramuzza et al.'s (2006) OCamCalib calibration toolbox, and the lens correction tool in Adobe Photoshop. As an example, we used OCamCalib to undistort the camera raw image of a dye release on 15 December 2013 (Figs. 2a,b). Analysis of the lens correction using the corresponding chessboard test showed an rms error of 1.51 pixels. Hößler and Landgraf (2014) showed that subpixel accuracy of the GoPro camera calibration is possible using a specifically designed calibration room. However, for the purpose of this study, the relatively quick camera calibration with OCamCalib provides sufficient accuracy.

\section{d. Mission planning}

Dominant processes in the surfzone typically have time scales on the order of seconds to minutes, requiring images to be obtained every few seconds to properly resolve surfzone kinematics. During our missions, we used the camera's time-lapse function at a sample rate of $0.5 \mathrm{~Hz}$ with a photo resolution of 12 megapixels $(4000 \times 3000$ pixels). Higher sample frequencies up to $2 \mathrm{~Hz}$ are possible, but the process of obtaining the image interrupts the video stream to the operators, reducing real-time evaluation of the focus area. To obtain a near-continuous dataset, we flew two UAVs in cyclical deployments. When the UAV battery of the first UAV reached its lower limit, the second was launched to relieve it. Both vehicles were programmed autonomously to loiter at the same location to ensure that the observation position was constant. This cycling scheme allowed an UAV to be on station almost continuously. To increase the temporal coverage, the UAV batteries were charged on-site using a portable gasoline-powered generator. Fortuitously, this setup was sustainable, such that each cycle, defined as the duration to execute a mission, land, and takeoff, was equivalent to the battery charge time.

\section{Results}

\section{a. Georectification}

To use the aerial images to complement the available in situ data, it is necessary to project the two-dimensional (2D) image plane onto a three-dimensional (3D) geographic plane. The camera calibration defines the relation between the $2 \mathrm{D}$ image and the 3D geographic plane. In general, camera calibration consists of two steps (e.g., Holland et al. 1997). First, the lens distortion has to be removed from the images (see section 2c), after which a perspective transformation is applied to project the $2 \mathrm{D}$ image plane onto the 3D geographic plane. To find the necessary transformation matrix (see, e.g., Hartley and Zisserman 2003, part 1), it is necessary to relate ground control points (GCPs) pixel locations in the undistorted image (Fig. 2b) to their known GPS location in the real world. During SCOPE, there were land-based GCPs, which were blue rectangular tarps on the beach (red squares), and water-based GCPs, which were pink boogie boards anchored to the bottom outside the surfzone (white circles). Each experiment day the contours of the tarps were surveyed using real-time kinematic (RTK) GPS that is accurate to $O(1 \mathrm{~cm})$. The boogie boards were equipped with a GT31 GPS that is accurate to $O(2-3 \mathrm{~m})$. Using the transformation matrix, the image is projected onto the geographic plane. The result is referred to as an orthophoto (see Fig. 2c). For Fig. 2c the pixel resolution ranges between approximately 0.035 and $0.7 \mathrm{~m}$. These values depend on the flying altitude and camera inclination, among others, and thus on the area covered by the orthophoto. The maximum and mean reprojection error-that is, the difference between the surveyed GPS location of a GCP and the location of the GCP obtained from the orthophoto-are 1.22 and $0.71 \mathrm{~m}$, respectively. These errors are affected by the accuracy of 1) the GPS devices used to survey the GCPs, 2) the lens correction, and 3) locating the GCPs in the undistorted image, among others.

\section{b. System performance}

In using UAVs to monitor the surfzone, there are two important aspects to consider: 1) the loiter duration and 2) the loitering accuracy. Longer loiter durations result in longer continuous data acquisition with the UAV. 

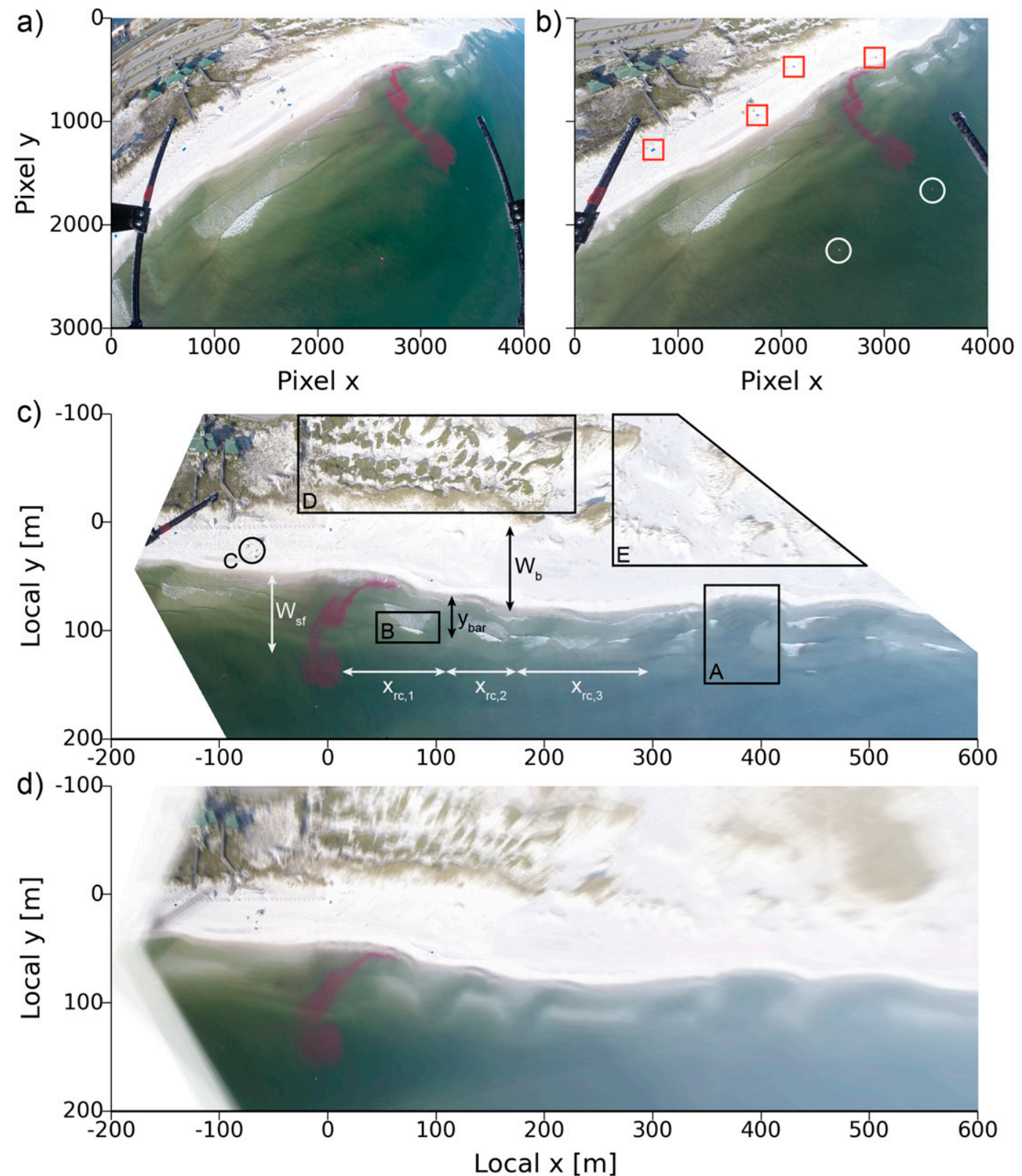

FIG. 2. Camera calibration process and georectification. (a) Distorted camera raw image of a dye release on 15 Dec 2013; (b) undistorted image-red squares and white circles indicate GCPs on the beach (blue tarps) and in the water (pink boogie boards); (c) orthophoto-from the orthophoto valuable surfzone characteristics can be obtained, such as beach width $W_{b}(x, t)$, surfzone width $W_{\mathrm{sf}}(x, t)$, possible rip channel location (rectangle A), rip channel spacing $x_{\mathrm{rc}}$, ${ }_{i}(t)$, areas of wave breaking or bar location (rectangle B), bar extent $y_{\mathrm{bar}}(x, t)$, people on the beach (circle C) vs people in the water (not present in this image), location of dune vegetation (rectangle D), location of dune development (rectangle E), accumulation of sea flora (not present in this image), and presence and location of marine mammals (not shown); and (d) time-exposure image of 100 consecutive orthophotos (200s) - used as a typical sandbar morphological product.

A high loitering accuracy of the UAV yields a stable FOV, making it easier to keep all GCPs used for the rectification procedure in view.

Regarding loiter duration, analysis of the log data of 36 SCOPE missions (18 for each vehicle) showed that the Y6 on average draws less power than the AT6 while loitering ( 325 and $505 \mathrm{~W}$, respectively). This results in longer loiter durations for the Y6 than for the AT6. The mean and maximum loiter duration are 9.63 and $11.61 \mathrm{~min}$ and 5.72 and $8.97 \mathrm{~min}$ for the Y6 and AT6, respectively. 
TABLE 2. UAV loitering accuracy data on 13 and 15 Dec 2013. SD denotes standard deviation.

\begin{tabular}{|c|c|c|c|c|}
\hline \multirow[b]{2}{*}{ Parameter } & \multicolumn{2}{|c|}{$13 \mathrm{Dec}$} & \multicolumn{2}{|c|}{$15 \mathrm{Dec}$} \\
\hline & AT6 & Y6 & AT6 & Y6 \\
\hline Mean wind strength ${ }^{\mathrm{a}}\left(\mathrm{m} \mathrm{s}^{-1}\right)$ & 2.48 & 2.6 & 5.15 & 5.36 \\
\hline SD wind strength ${ }^{\mathrm{a}}\left(\mathrm{m} \mathrm{s}^{-1}\right)$ & 0.39 & 0.52 & 0.40 & 1.07 \\
\hline Mean loiter power (W) & 516 & 329 & 502 & 318 \\
\hline Mean altitude $^{\mathrm{b}}(\mathrm{m})$ & 101.2 & 115 & 100.5 & 80 \\
\hline SD altitude $(\mathrm{m})$ & 2.8 & 4.2 & 3.5 & 4.62 \\
\hline Mean loiter radius ${ }^{\mathrm{c}}(\mathrm{m})$ & 2.70 & 1.06 & 3.36 & 1.68 \\
\hline $\operatorname{SD~loiter~radius~}^{\mathrm{c}}(\mathrm{m})$ & 1.02 & 0.56 & 0.80 & 0.22 \\
\hline Mean loiter error $(\mathrm{m})$ & 0.79 & 1.33 & 2.28 & 4.39 \\
\hline SD loiter error $(\mathrm{m})$ & 0.23 & 0.49 & 2.72 & 2.65 \\
\hline
\end{tabular}

${ }^{a}$ Obtained from an anemometer in the beach parking lot. Wind data were collected at a frequency of $20 \mathrm{~Hz}$ and binned in 1-s averages. These averages where then matched with the time stamps of the UAVs missions, resulting in a mean and SD of the wind strength for each day.

${ }^{\mathrm{b}}$ The Y6 loitered at slightly different altitudes despite being programmed to maintain the same altitude as the AT6. We think this was caused by an incorrectly programmed parameter in the autopilot.

${ }^{\mathrm{c}}$ Radius of the $90 \%$ watch circle (see Fig. 3a).

These durations depend primarily on battery type and age, flying style, and environmental conditions.

To analyze the loitering accuracy of the two UAVs, we focus our attention on the missions on 13 and 15 December 2013 (see Table 2; Fig. 3). During these missions we deployed the UAVs to fly to the same predefined waypoint in order to obtain a near-continuous dataset with a similar FOV. Defining a watch circle in which the UAV spends $90 \%$ of its time loitering (Fig. 3a), it follows that in general the AT6 has a larger loiter radius than the Y6 (see Table 2). In turn, there is less variability in the mean position of the AT6 compared to the Y6 (except for an AT6 outlier on 15 December; see Fig. 3b). These results suggest that the GPS of the AT6 is more accurate than the $\mathrm{Y} 6$, but that in turn the position holding correction gains of the Y6 are better calibrated than the AT6.

Furthermore, from relating collected wind data to each individual UAV mission on 13 and 15 December (Fig. 3b), it follows that the mean wind strength (for its definition see Table 2, footnote a) significantly influences the variability of the UAVs mean loiter error. However, we experienced that from an altitude around $100 \mathrm{~m}$ and wind speeds up to $10 \mathrm{~m} \mathrm{~s}^{-1}$, it is relatively easy to keep all the necessary GCPs in view.

\section{Application}

Rotary wing UAVs are flexible surfzone monitoring platforms, requiring about $1 \mathrm{~h}$ of set up, including placement of GCPs, that have the ability to loiter at a fixed position for several hours directly above or seaward of the surfzone. In addition, the resulting moderate spatial resolution and high temporal resolution images can be georectified with good accuracy. These assets make them highly suitable to extract surfzone characteristics and investigate surfzone kinematics on the key
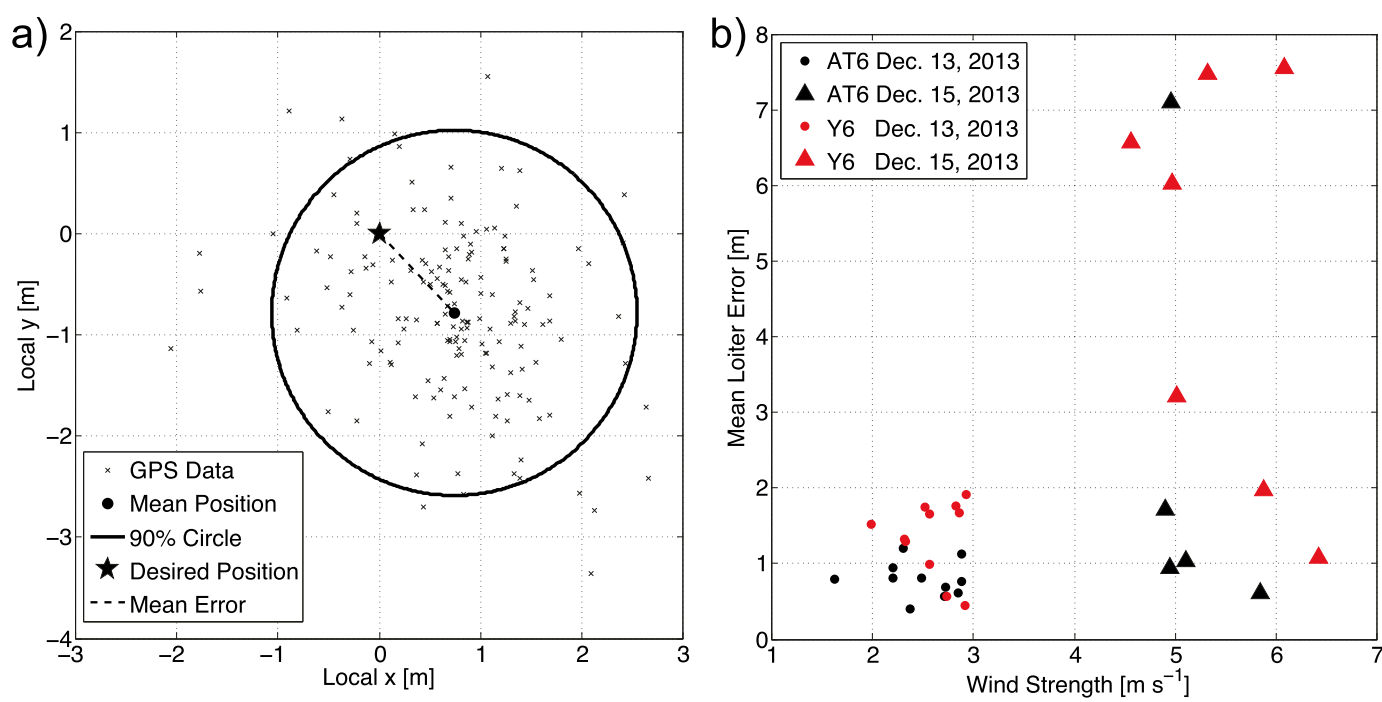

FIG. 3. Loitering accuracy of the UAVs as a function of the mean wind strength. (a) Definition of the watch circle: local $x$ aligns with the alongshore direction, local $y$ aligns with the cross-shore direction, the black dot is the mean of all the GPS loiter points, the star is the desired position (i.e., the predefined waypoint), and the dashed line is the mean error, i.e., the distance between the mean position and the desired position. (b) Effect of the mean wind strength (for definition see Table 2, footnote a) on the mean loitering accuracy of both UAVs. 

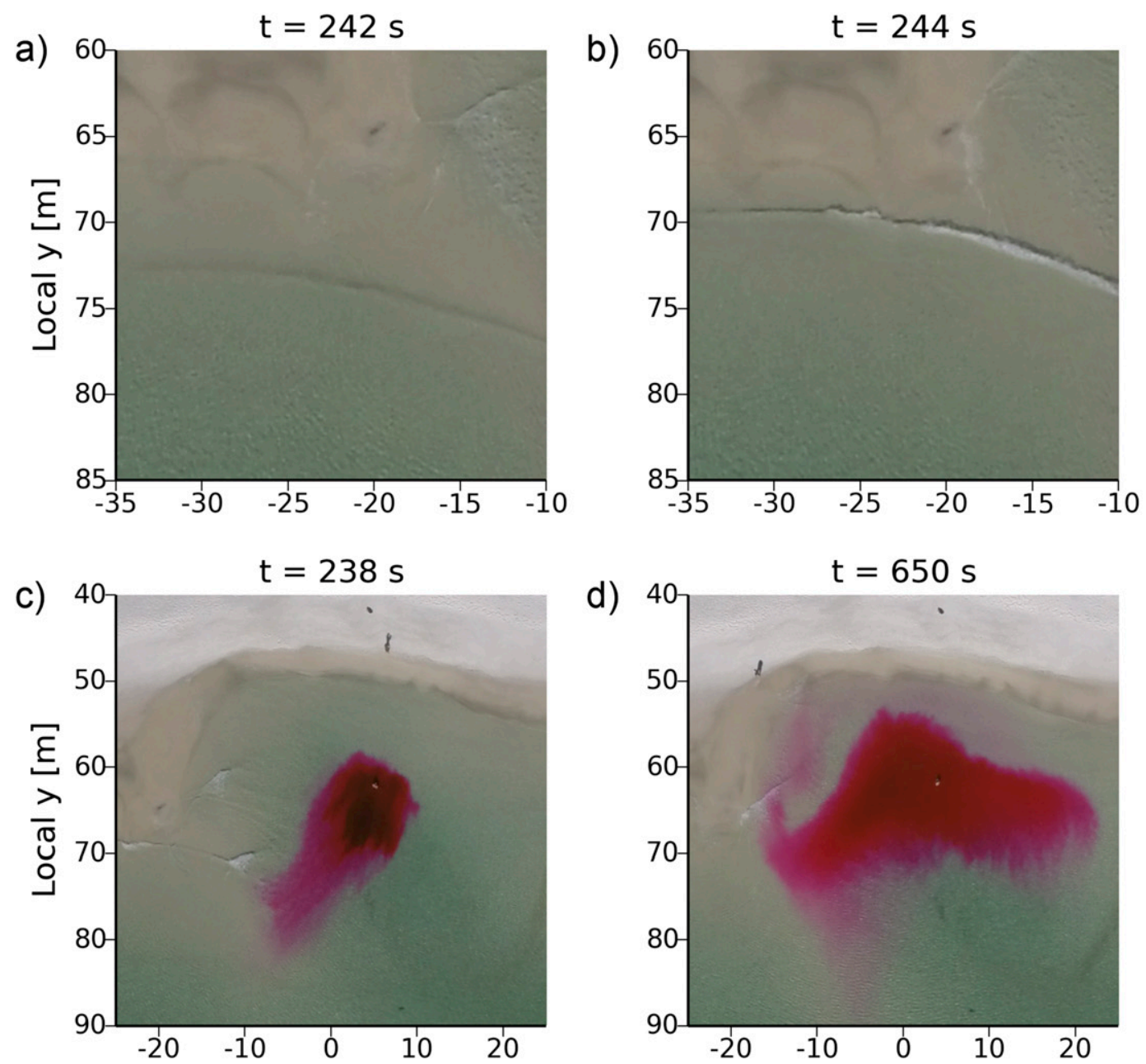

d)
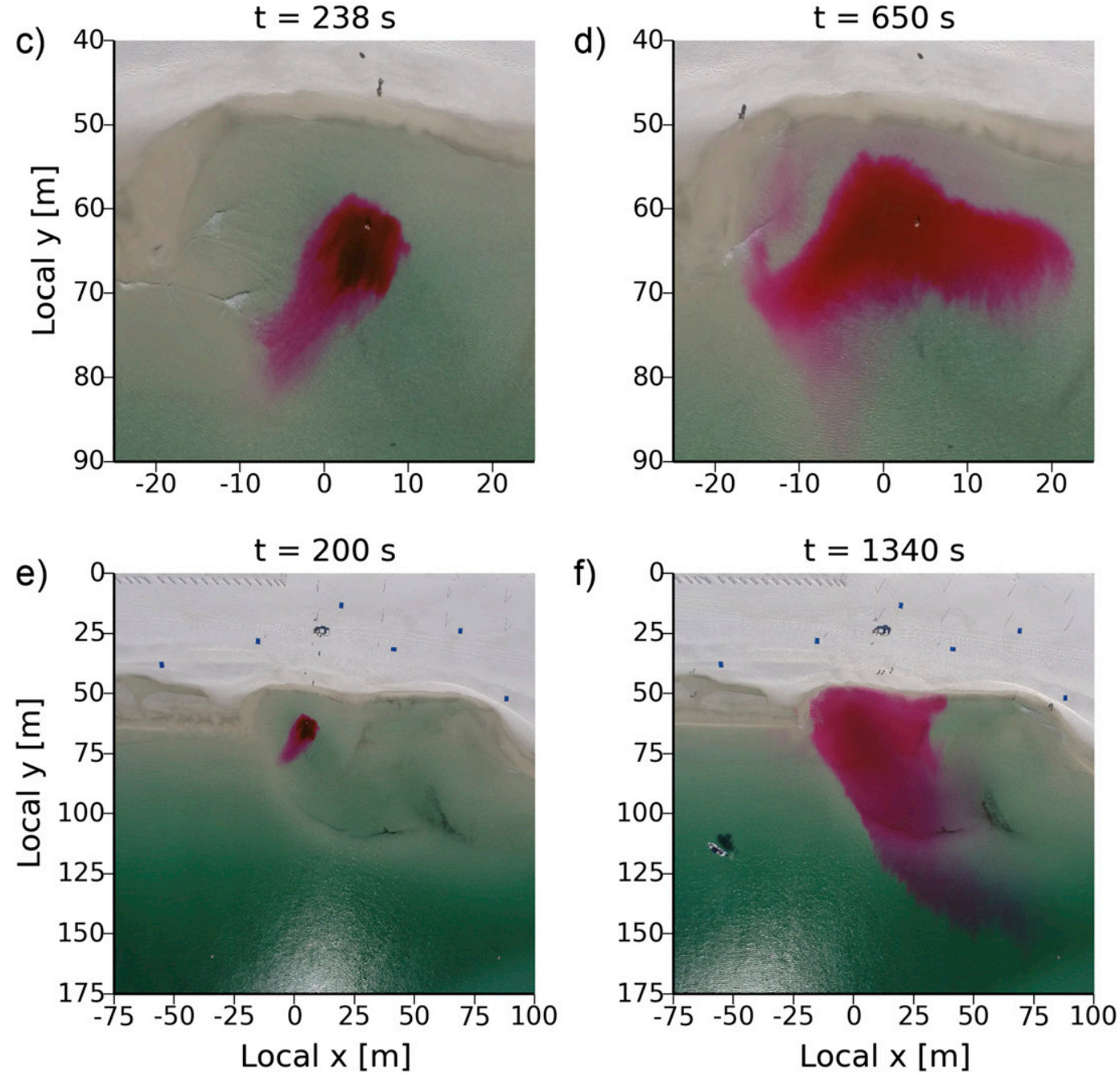

FIG. 4. Examples of capturing surfzone kinematics on different scales. (a),(b) Tracking of individual waves and wave breaking characteristics with a spatial scale of $O(\mathrm{~m})$ and a temporal scale of $O(\mathrm{~s})$. (c),(d) Evolution of the spreading of a dye cloud with a spatial scale of $O(10 \mathrm{~m})$ and a temporal scale of $O(10 \mathrm{~min})$. (e),(f) Evolution of a dye cloud with a spatial scale of $O(100 \mathrm{~m})$ and a temporal scale of $O(30 \mathrm{~min})$. Here, $t$ is the time after dye deployment. 
spatial and temporal scales. A single orthophoto already provides much valuable information about the surfzone that is otherwise tedious or difficult to obtain; see Fig. 2c for some examples. Additionally, averaging successive orthophotos over a certain period returns a so-called time-exposure image, commonly used in sandbar morphology and rip current studies (e.g., Lippmann and Holman 1989); see Fig. 2d. As a result, UAV can, for instance, be used pre- and poststorm/hurricane to quickly identify and measure important morphological changes (by using single orthophotos) or as a day-today beach safety tool to locate possible dangerous areas where strong (rip) currents might occur (by using a time-exposure image).

The ability to obtain consecutive orthophotos with similar FOV permit new opportunities in the scientific pursuit of surfzone kinematics at different spatial and temporal scales. For example, on the smallest scales of $O(1 \mathrm{~m})$ and $O(1 \mathrm{~s})$, it is possible to track individual wave crests (see Figs. 4a,b), which provide a quantitative spatial pattern of wave celerity and dissipation. This information can be used to estimate surfzone bathymetry using algorithms such as Beach Wizard (van Dongeren et al. 2008) or cBathy (Holman et al. 2013). The latter algorithm was used by Holman et al. (2011) on aerial imagery from a fixed wing UAV (short and gappy data in time and unsteady in aim compared to rotary wing UAV data) already showing reasonable comparison between estimated bathymetry and ground truth data. In turn, the spatial patterns in wave dissipation can be evaluated to understand the formation of surfzone eddies (MacMahan et al. 2004; Spydell and Feddersen 2009) on the intermediate spatial, $O(10 \mathrm{~m})$, and temporal scale, $O(10 \mathrm{~min})$, (see Figs. $4 \mathrm{c}$,d) that affect the rip current kinematics and thereby swimmer safety. On the same scale, dye releases yield estimates of tracer dispersion (Grant et al. 2005) and concentration (Clark et al. 2014), and eddy diffusivity (Bogucki et al. 2005). On the largest spatial, $O(100 \mathrm{~m}-1 \mathrm{~km})$, and temporal scales, $O(30 \mathrm{~min}$-hours $)$, the evolution of a dye cloud can be used to investigate the residence time of material in the surfzone (Reniers et al. 2009) and the exchange of material between the surfzone and inner shelf (see Figs. 4e,f).

\section{Summary}

Here, we describe an exciting new potential of rotary wing UAVs for monitoring the surfzone. The UAVs are extremely flexible surveying platforms that can gather near-continuous moderate spatial resolution and high temporal resolution images from a fixed position high above a study site that has previously been difficult to obtain. The georectified images are accurate to $O(1 \mathrm{~cm}-1 \mathrm{~m})$ based on pixel resolution. There are a number of creative approaches that can be performed to quickly obtain surfzone and beach characteristics in response to storms or for day-to-day beach safety information, as well as scientific pursuits of surfzone kinematics on different spatial and temporal scales, and dispersion and advection estimates of pollutants.

Acknowledgments. RB and MS are supported by the ERC-Advanced Grant 291206-NEMO. Furthermore, this research was funded by a grant from BP's Gulf of Mexico Research Initiative. The authors thank two anonymous reviewers for their constructive comments.

\section{REFERENCES}

Battjes, J. A., 1988: Surf-zone dynamics. Annu. Rev. Fluid Mech., 20, 257-291, doi:10.1146/annurev.fl.20.010188.001353.

Bogucki, D. J., B. H. Jones, and M.-E. Carr, 2005: Remote measurements of horizontal eddy diffusivity. J. Atmos. Oceanic Technol., 22, 1373-1380, doi:10.1175/JTECH1794.1.

Bouguet, J.-Y., cited 2014: Camera calibration toolbox for MATLAB. [Available online at http://www.vision.caltech. edu/bouguetj/calib_doc/.]

Clark, D. B., L. Lenain, F. Feddersen, E. Boss, and R. T. Guza, 2014: Aerial imaging of fluorescent dye in the near shore. J. Atmos. Oceanic Technol., 31, 1410-1421, doi:10.1175/ JTECH-D-13-00230.1.

Dalrymple, R. A., J. H. MacMahan, A. J. H. M. Reniers, and V. Nelko, 2011: Rip currents. Annu. Rev. Fluid Mech., 43, 551581, doi:10.1146/annurev-fluid-122109-160733.

Grant, S. B., J. H. Kim, B. H. Jones, S. A. Jenkins, J. Wasyl, and C. Cudaback, 2005: Surf zone entrainment, along-shore transport, and human health implications of pollution from tidal outlets. J. Geophys. Res., 110, C10025, doi:10.1029/ 2004JC002401.

Hartley, R. I., and A. Zisserman, 2003: Multiple View Geometry in Computer Vision. 2nd ed. Cambridge University Press, 665 pp.

Heikkilä, J., and O. Silvén, 1997: A four-step camera calibration procedure with implicit image correction. Proceedings of the 1997 IEEE Computer Society Conference on Computer Vision and Pattern Recognition, D. Plummer and I. Torwick, Eds., IEEE, 1106-1112, doi:10.1109/CVPR.1997.609468.

Hodgson, A., N. Kelly, and D. Peel, 2013: Unmanned aerial vehicles (UAVs) for surveying marine fauna: A Dugong case study. PLoS ONE, 8, e79556, doi:10.1371/journal.pone.0079556.

Holland, K. T., R. A. Holman, T. C. Lippmann, J. Stanley, and N. Plant, 1997: Practical use of video imagery in nearshore oceanographic field studies. IEEE J. Oceanic Eng., 22, 81-92, doi:10.1109/48.557542.

Holman, R. A., and J. Stanley, 2007: The history and technical capabilities of Argus. Coastal Eng., 54, 477-491, doi:10.1016/ j.coastaleng.2007.01.003.

_ K. T. Holland, D. M. Lalejini, and S. D. Spansel, 2011: Surf zone characterization from Unmanned Aerial Vehicle imagery. Ocean Dyn., 61, 1927-1935, doi:10.1007/s10236-011-0447-y.

_ N. Plant, and T. Holland, 2013: cBathy: A robust algorithm for estimating nearshore bathymetry. J. Geophys. Res. Oceans, 118, 2595-2609, doi:10.1002/jgrc.20199. 
Hößler, T., and T. Landgraf, 2014: Automated traffic analysis in aerial images. Computer Vision and Graphics, L. J. Chmielewski et al., Eds., Lecture Notes in Computer Science, Vol. 8671, Springer International Publishing, 262-269, doi:10.1007/978-3-319-11331-9_32.

Kannala, J., and S. S. Brandt, 2006: A generic camera model and calibration method for conventional, wide-angle, and fish-eye lenses. IEEE Trans. Pattern Anal. Mach. Intell., 28, 1335-1340, doi:10.1109/TPAMI.2006.153.

Lippmann, T. C., and R. A. Holman, 1989: Quantification of sand bar morphology: A video technique based on wave dissipation. J. Geophys. Res., 94, 995-1011, doi:10.1029/ JC094iC01p00995.

MacMahan, J. H., A. J. H. M. Reniers, E. B. Thornton, and T. P. Stanton, 2004: Surf zone eddies coupled with rip current morphology. J. Geophys. Res., 109, C07004, doi:10.1029/ 2003JC002083.

Peregrine, D. H., 1998: Surf zone currents. Theor. Comput. Fluid Dyn., 10, 295-309, doi:10.1007/s001620050065.

Rasmussen, J., J. Nielsen, F. Garcia-Ruiz, S. Christensen, and J. C. Streibig, 2013: Potential uses of small unmanned aircraft systems (UAS) in weed research. Weed Res., 53, 242-248, doi:10.1111/wre.12026.

Reniers, A. J. H. M., J. H. MacMahan, E. B. Thornton, T. P. Stanton, M. Henriquez, J. W. Brown, J. A. Brown, and E. Gallagher, 2009: Surf zone surface retention on a ripchanneled beach. J. Geophys. Res., 114, C10010, doi:10.1029/ 2008JC005153.

Rinaudo, F., F. Chiabrando, A. Lingua, and A. Spanò, 2012: Archeological site monitoring: UAV photogrammetry can be an answer. Proceedings of the XXII ISPRS Congress:
Imaging a Sustainable Future, M. Shortis, and J. Mills, Eds., International Archives of the Photogrammetry, Remote Sensing and Spatial Information Sciences, Vol. XXXIX-B5, $583-588$.

Rogers, K., and A. Finn, 2013: Three-dimensional UAV-based atmospheric tomography. J. Atmos. Oceanic Technol., 30, 336-344, doi:10.1175/JTECH-D-12-00036.1.

Scaramuzza, D., A. Martinelli, and R. Siegwart, 2006: A toolbox for easy calibrating omnidirectional cameras. 2006 IEEE/ RSJ International Conference on Intelligent Robots and Systems (IROS 2006), IEEE, 5695-5701, doi:10.1109/ IROS.2006.282372.

Spydell, M., and F. Feddersen, 2009: Lagrangian drifter dispersion in the surf zone: Directionally spread, normally incident waves. J. Phys. Oceanogr., 39, 809-830, doi:10.1175/2008JPO3892.1.

Tsai, R. Y., 1987: A versatile camera calibration technique for highaccuracy 3D machine vision metrology using off-the-shelf TV cameras and lenses. IEEE J. Rob. Autom., 3, 323-344, doi:10.1109/JRA.1987.1087109.

van Dongeren, A., N. Plant, A. Cohen, D. Roelvink, M. C. Haller, and P. Catalán, 2008: Beach Wizard: Nearshore bathymetry estimation through assimilation of model computations and remote observations. Coastal Eng., 55, 1016-1027, doi:10.1016/ j.coastaleng.2008.04.011.

Zhang, C., and J. M. Kovacs, 2012: The application of small unmanned aerial systems for precision agriculture: A review. Precis. Agric., 13, 693-712, doi:10.1007/s11119-012-9274-5.

Zhang, Z., 1999: Flexible camera calibration by viewing a plane from unknown orientations. The Proceedings of the Seventh IEEE International Conference on Computer Vision, B. Werner, Ed., Vol. 1, IEEE, 666-673, doi:10.1109/ICCV.1999.791289. 